\title{
Review
}

\section{Immunomodulatory effects of lactoferrin}

\author{
Tania SIQUEIROS-CENDÓN ${ }^{1}$, Sigifredo ARÉVALO-GALLEGOS ${ }^{2}$, Blanca Flor IGLESIAS-FIGUEROA² ${ }^{2}$ Isui Abril \\ GARCÍA-MONTOYA², José SALAZAR-MARTÍNEZ ${ }^{3}$, Quintín RASCÓN-CRUZ ${ }^{2, *}$
}

${ }^{1}$ Laboratorio de Inmunología, Facultad de Ciencias Químicas, Universidad Autónoma de Chihuahua, Circuito 1, Nuevo Campus Universitario, CP 31125, Chihuahua, México; ${ }^{2}$ Laboratorio de Biotecnología I, Facultad de Ciencias Químicas, Universidad Autónoma de Chihuahua, Circuito 1, Nuevo Campus Universitario, CP 31125, Chihuahua, México; ${ }^{3}$ Proteo/Muuu-Technologies de México, Zaragoza 63, Zona Centro, Fco. I. Madero, Coahuila, México

Lactoferrin (Lf) is an iron-binding glycoprotein of the transferrin family, which is expressed in most biological fluids with particularly high levels in mammalian milk. Its multiple activities lie in its capacity to bind iron and to interact with the molecular and cellular components of hosts and pathogens. Lf can bind and sequester lipopolysaccharides, thus preventing pro-inflammatory pathway activation, sepsis and tissue damages. Lf is also considered a cell-secreted mediator that bridges the innate and adaptive immune responses. In the recent years much has been learned about the mechanisms by which Lf exerts its activities. This review summarizes the recent advances in understanding the mechanisms underlying the multifunctional roles of Lf, and provides a future perspective on its potential prophylactic and therapeutic applications.

Keywords: lactoferrin; glycoprotein; transferring; immunomodulator; antimicrobial

Acta Pharmacologica Sinica (2014) 35: 557-566; doi: 10.1038/aps.2013.200

\section{Introduction}

The first literature references to lactoferrin (Lf) refer to it as a "red protein from milk" and, from the time that it was first purified $^{[1,2]}$, as an iron-binding protein. Lf is an $80-\mathrm{kDa}$ glycosylated protein of approximately 700 amino acids with high homology among species that is considered a multifunctional glycoprotein that is widely distributed in colostrum and milk ${ }^{[3]}$ as well as in other secretions, such as tears and saliva ${ }^{[4]}$. It is released from neutrophils in the blood and inflamed tissues. Lf has a direct antimicrobial role, as it limits the proliferation and adhesion of microbes (eg, bacteria, viruses and parasites) and/or kills them ${ }^{[5]}$. This effect of Lf is the result of its ability to sequester iron in biological fluids and destabilize the membranes of microorganisms ${ }^{[6]}$. The metals that Lf binds are the $\mathrm{Fe}^{2+}$ or $\mathrm{Fe}^{3+}$ ions, but it can exist free of $\mathrm{Fe}^{3+}$ (apo-Lf). Human LF (hLF) is a polypeptide chain that is folded into two symmetrical lobes ( $\mathrm{N}$ and $\mathrm{C}$ lobes) that are connected by a hinge region that contains parts of an a-helix (Figure 1).

It is known that Lf possesses antimicrobial activities, modulates the overall immune response and protects against viral infections, and its role against septic shock has already been well described $^{[5,6]}$. In this respect, it is noteworthy that Lf

\footnotetext{
* To whom correspondence should be addressed.

E-mail qrascon@uach.mx

Received 2013-10-28 Accepted 2013-12-23
}

concentrations are locally elevated in inflammatory disorders, including neurodegenerative diseases ${ }^{[7]}$, inflammatory disease, arthritis ${ }^{[8]}$ and allergic inflammation ${ }^{[9]}$. The cellular and molecular mechanisms responsible for the immunomodulatory effects of Lf are not fully elucidated, and in vitro and in vivo studies suggest the existence of multiple mechanisms that include modulation of cytokine/chemokine production, regulation of the production of reactive oxygen species and immune cell recruitment ${ }^{[10]}$.

Lf, which functions as a natural iron scavenger and an activator/modulator of signaling pathways, leads to the negative feedback of the inflammatory response, as shown by a decrease in the production of reactive oxygen species and various pro-inflammatory cytokines ${ }^{[11,12]}$.

Lf secretion dramatically increases during inflammation and neurodegenerative diseases, which leads to neutrophil degranulation and the activation of microglial cells ${ }^{[13]}$. The increase of Fe during hemorrhagic stroke in microglia is due to the uptake of the transferrin and lactoferrin receptors. Lactoferrin receptors (LfR; $105 \mathrm{kDa}$ ) on neurons are involved in the transferrinindependent pathway by transporting iron from iron-containing Lf across neuron membranes ${ }^{[14]}$. Future research on iron metabolism and its dysregulation may provide new insights into neurodegenerative diseases such as Alzheimer's, Parkinson's, and Friedrich's ataxia ${ }^{[15]}$.

Lf also acts as a first-line of defense by significantly impact- 


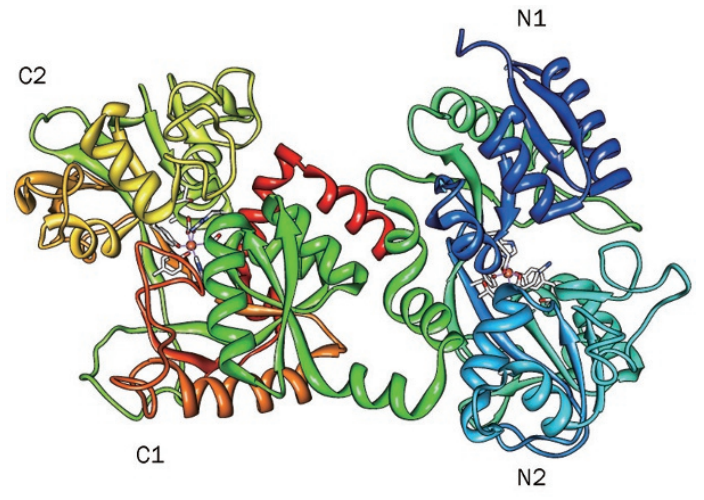

Figure 1. Predicted structure of Lf from the EU812318 (bLF) sequence using PDB ID: 1FCK (human) as a template showing a two-lobed, fourdomain polypeptide. Modeled using Protein Model Portal and viewed using the Chimera software (http://www.cgl.ucsf.edu/chimera/).

ing the development of adaptive immune responses. Iron sequestration by Lf reduces oxidative stress that alters the extension and production of cytokines ${ }^{[16]}$. Lf has a strong modulatory effect on the adaptive immune system by accelerating the maturation of T-cell precursors into competent helper cells and by the differentiation of immature B-cells into antigen-presenting cells ${ }^{[17]}$. Lf can also modulate innate and adaptive immunities because it binds to LPS and CD-14 and interferes with the formation of the CD14-LPS complex, resulting in attenuation of the LPS/CD-14/TLR-4 signaling pathway, which is essential for the pathogenesis of sepsis ${ }^{[18]}$. Lf may stimulate the immune system by binding to CD-14 and then activating the TLR-4-mediated pathway while preventing overexpression of LPS-induced inflammation ${ }^{[19]}$.

Lf blocks the signal transduction between LPS and the CD14-TLR complex that exists in the macrophages to prevent or treat septic shock. Lf promotes the maturation of B- and $\mathrm{T}$-cells in function and phenotype to improve the immune response $^{[20]}$. Thus, Lf may also protect infants from infections due to its large set of ability's against the direct interaction with microorganisms and through its immune modulatory effect.

\section{Immunomodulators}

Immunomodulators are biological or synthetic substances that are capable of altering the immune response by augmenting or reducing immune system components, including the innate and adaptive arms of the immune response ${ }^{[21]}$. The human body produces some peptides and small proteins with antimicrobial and immunomodulatory activities ${ }^{[22]}$. At first, it was thought that the function of these peptides was only to kill microorganisms; however, it is now known that these peptides also coordinate multiple immune system functions as a basic immunity mechanism ${ }^{[23]}$. These peptides are believed to contribute to the prevention or recovery of changes in the immune system by suppressing or enhancing the immune response $\mathrm{e}^{[24]}$. Some immunomodulators, such as antibodies, react to unique antigens and may be specific to certain pathogens, but others can be nonspecific (eg, cytokines, antimicrobial peptides, drugs and even microorganisms used to generate a positive host response). A clear example of this is the use of probiotics to enhance the normal microbiome of the small intestine ${ }^{[17]}$. With this approach, immunomodulators may be classified as immunoadjuvants, immunosuppressants or immunostimulators.

Immunoadjuvants are substances that are required to elicit a maximal T-cell response to microbial antigens. They are commonly used in vaccine development to improve the response of the organism ${ }^{[25,26]}$. Immunosuppressants inhibit the normal functioning of the immune system; therefore, they are used in conjunction with drugs to treat autoimmune diseases and the immune response in transplantation ${ }^{[27]}$. Immunostimulators are agents that act through response-mediated innate and adaptive immunity. In healthy individuals, immunostimulators act as prophylactic agents to enhance the immune response to infection. In immunocompromised individuals, immunostimulators may act as natural therapy ${ }^{[28]}$.

\section{Immunomodulators in infant formulas}

Colostrum, the first milk produced by the mammary glands of mammals after giving birth, contains elements with immunomodulatory properties, and these elements have attracted the attention of some pharmaceutical and nutritional industries as a dietary supplement ${ }^{[29]}$. Lf is present in bovine colostrum at a concentration of $500 \mathrm{mg} / 100 \mathrm{~g}$ and is a GRAS (generally recognized as safe) product that is currently used in several countries as a supplement for infants. To date, no adverse effects regarding its use have been documented ${ }^{[30]}$. The first occurrence of an infant formula containing Lf was in Japan in 1986, and this product, which was called "BF-L dry milk", was marketed by the Morigana Milk Industry. Currently, Lf can be found in various products, such as yogurt, pet food, cream, and milk and other beverages ${ }^{[31]}$.

\section{Lactoferrin competence in early life response Colostrum and lactoferrin}

The concentration of Lf in human colostrum is $5.3 \pm 1.9$ $\mathrm{mg} / \mathrm{mL}$, and, after the first month of lactation, this value is approximately $1 \mathrm{mg} / \mathrm{mL}^{[32]}$. Colostrum is the pre-milk fluid in the mammary gland of female mammals immediately before giving birth. After the first instance of nursing, the fluid transforms to milk over a period of 2-3 $\mathrm{d}$. In all non-human mammals, colostrum is crucial to the survival of the newborn because high concentrations of immune factors are transferred to the newborn via colostrum. In humans, some immunofactors are transferred through the placenta. Human colostrum is particularly beneficial; however, if a human newborn does not receive colostrum, death is not imminent as it is in other mammals. Like in other mammals, a newborn's first meal of colostrum significantly impacts its health and well-being, and the effect lasts the rest of its life. Because a newborn's immune system is not fully developed, it is highly susceptible to pathogens, antigens and allergens ${ }^{[26]}$. The colostrum that is found in breast milk contains all of the immune factors that are essen- 
tial to activate and regulate the immune system response. Consequently, colostrum plays a crucial role in supporting a newborn's immune system while it develops. In trials, significant quantities of intact Lf was found in infant stools, even in babies of 4 months old, which suggests that Lf can survive being active in the small intestine. The values decline from $155 \mathrm{mg} / 24 \mathrm{~h}$ at 1 week of age to $20 \mathrm{mg} / 24 \mathrm{~h}$ at 14 weeks, whereas Lf intake from breast milk was $2.5 \mathrm{~g} / 24 \mathrm{~h}$ at 1 week to $1.4 \mathrm{~g} / 24 \mathrm{~h}$ at 14 weeks $^{[33]}$.

$\mathrm{Lf}$ is the first line of defense for any entry point in the body. It is found in small quantities in most body fluids such as saliva, tears, nasal secretions and intestinal fluids (eg, bile), as well as in neutrophils (the secondary granules of white blood cells). Lf is synthesized by the mucosal lining (eg, in the mouth or intestinal tract) and neutrophils, and it is released in response to inflammatory stimuli. The low physiologic serum levels of Lf increase significantly upon host infection. The Lf receptor was studied and isolated from activated $\mathrm{T}$ - and B-cells, monocytes, intestinal brush border cells, platelets and neoplastic cells ${ }^{[34]}$. Lf inhibits neutrophil apoptosis via blockade of proximal apoptotic signaling events. Iron-unsaturated apo-lactoferrin inhibits spontaneous apoptosis in human neutrophils, depending upon the iron saturation status, and down regulates early events in the apoptosis process; moreover, its effect is evident in an established phase of rheumatic arthritis $^{[35]}$.

\section{Mucosal immunity}

Lactoferrin, amylase and lysozyme are detectable proteins during the early fetal stages of development. Only low levels of these secretory components are observed before week 29 of gestation, but their levels increase rapidly to adult levels one week after being born. Although the skin and gastrointestinal tracts are immunologically mature prior to birth, the respiratory tract is not ${ }^{[36]}$.

\section{Development of the fetal immune system}

The first stage of human fetal hematopoiesis occurs in the mesoderm of the yolk sac and in the mesenchymal tissue. Totipotent erythroid and granulomacrophage progenitors can be found in human embryonic structures 3-4 weeks into gestation. These primitive cells can then be detected in circulation after 4 weeks of gestation, and they then migrate to the liver, which is known as the site of hematopoiesis. At approximately 5-10 weeks, the liver undergoes a dramatic increase in size as the number of nucleated cells rises. These early progenitors proliferate but undergo remarkably little differentiation. Hepatic hematopoiesis declines in the third trimester and ceases soon after birth ${ }^{[36-38]}$.

Lf expression can be detected at the 2- and 4-cell stages of embryonic development and throughout the blastocyst stage (prior to implantation). After implantation, Lf expression cannot be detected again until approximately halfway through gestation, when it can be found in neutrophils and epithelial cells of the developing reproductive and digestive systems ${ }^{[39]}$. The Lf plasma levels are higher during pregnancy than in either male or female adults, and these levels show a progressive increase leading up to week 29, at which point these levels remain high $^{[40]}$. Several factors may explain this increase, such as pregnancy-associated leukocytosis, the selective increase of Lf in neutrophil granules or endometrial tissues or contribution from the decidua and mammary glands ${ }^{[41]}$. Lf acts as a growth factor activator and, when compared to epidermal growth factor, the effects of Lf alone on small intestine epithelial cells are more potent and can stimulate the proliferation of endometrium stromal cells ${ }^{[39]}$.

\section{Development of immune competence stimulated by microorganisms}

The principal stimuli that induce the postnatal maturation of the mammalian immune system are signals from the microbial environment, particularly the commensal microflora of the gastrointestinal tract, but infections in the gastrointestinal and respiratory tracts may also contribute to immune system development ${ }^{[42]}$. Lf is identified as an important defense component of colostrum and mature milk, which promotes the hypothesis that its function involves the protection of neonatal gut barriers. In concurrence with this finding, LfR were discovered in the small intestine during a study of iron delivery to the duodenal mucosa ${ }^{[43]}$. A recent study of LfR in the mouse small intestine suggests that LfR may act as the main iron source during the early stages of life. Subsequent binding affinity studies identified Lf on the surface of B-cells, T-cells and monocytes, as well as on platelets and intestinal cells ${ }^{[17,43]}$. Lf can facilitate the adaptation of an infant intestine because Lf hydrolysis is minimal at the prevailing postprandial $\mathrm{pH}$ in infants; therefore, Lf may have greater biological potential in infants than in adults. Lf bi-directionally stimulates the proliferation and differentiation of small intestinal epithelial cells, which are concentration-dependent and affect the mass, length and epithelial digestive enzyme expression of the small intestines $^{[44]}$.

The constant interaction between the intestinal epithelium and the gut microbiota is a challenge for the preterm gut. Mature intestines have many physical barriers that are designed to limit bacterial access to the gut lumen and prevent attachment and translocation across the intestinal epithelium. In contrast, external factors render the preterm intestine more susceptible to microbial interaction and translocation. Preterm infants face many challenges when transitioning from the in utero to extrauterine environment. Failure in the maturation of the preterm gut to accommodate bacteria and food leads to significant morbidity, such as neonatal necrotizing enterocolitis $^{[45]}$.

\section{Role of lactoferrin in the immune system}

\section{Interaction of lactoferrin with Antigen Presenting Cells}

Among the Antigen Presenting Cells (APCs), macrophages (Mf), dendritic cells (DCs) and B-cells are of critical importance for the maintenance of tissue homeostasis and the innate response; and this response occurs via the major histocompatibility complex II (MHC II), as well as by linking the innate and 
adaptive immune responses. Mfs are highly phagocytic cells that play a central role in the control of infections, either by the direct intracellular killing of microorganisms or the secretion of cytokines to inhibit the replication of microorganisms. Mfs are also involved in type II inflammation and tissue repair processes $^{[46-48]}$. DCs are a heterogeneous population of cells that are highly specialized for antigen recognition; and they play a key role in the immune system because they control the induction of immunity and tolerance. B-cells utilize specific surface receptors to capture foreign antigens and present their associated epitopes to T-cells ${ }^{[4,50]}$.

\section{Macrophages}

Macrophages (Mfs) are Antigen Presenting Cells (APCs), and their role in the innate immune response involves inducing the phagocytosis of foreign particles and subsequently releasing pro-inflammatory mediators. Mfs also enable cross-talk between the innate and adaptive immune systems to stimulate antigen-specific $T$ cells. Active binding studies revealed that Lf receptors are located on the surface of Mf in bovine and human models ${ }^{[51,52]}$. Lf also contributes to the suppression of pro-inflammatory cytokines and type I interferon (IFN $\alpha / \beta$ ) induction ${ }^{[53,54]}$, and it affects the ability of Mfs to present antigens for antigen-specific CD4+ T-cells in the adaptive immune system. Lf can increase the phagocytic activity of Mfs that are infected or have not yet been activated ${ }^{[5,56]}$. IL-12, one of the major cytokines that are produced by Mfs, is a key modulator of IFNa. The main role of IL-12 at the site of infection is to recruit $\mathrm{Mf}^{[57,58]}$, and it acts as a co-stimulator to maximize the secretion of IFNa from differentiated Th1 cells and memory $\mathrm{T}_{\text {-cells }}{ }^{[59]}$. Up-regulation of adhesion molecules on the surface of the endothelium plays a key role in the recruitment and infiltration of leukocytes at inflammation sites. Lf strongly inhibits TNF-a-stimulated expression of ICAM-1 by competing with NF-jB in endothelial cells, which suggests that Lf reduces inflammatory events and the development of inflammatory diseases such as atherosclerosis ${ }^{[60]}$.

\section{Dendritic cells}

Dendritic cells (DCs) are a group of functionally related phagocytic cells that can manipulate T-cell differentiation ${ }^{[61]}$ and redirect memory T-cell functions ${ }^{[62,63]}$. DCs play an important role in triggering $\mathrm{T}$-cell responses that lead to the secretion of Th1 cytokines ${ }^{[64,65]}$. It has also been shown that $\beta$-defensin 2, another key innate immunity molecule, acts directly on DCs to induce their functional maturation and enable them to elicit a Th1 response ${ }^{[66,67]}$.

The ability of Lf to promote antigen-specific delayed-type hypersensitivity (DTH) responses and to activate bacillus Calmette-Guerin (Mycobacterium strain) (BCG)-specific T cells suggests that Lf plays a role in the initiation of T-cell activation through the modulation of dendritic cell function ${ }^{[68]}$. Dendritic cells possess Lf receptors because bovine and human Lf binds to the surface of peripheral blood-derived dendritic cells ${ }^{[69]}$. The ability of dendritic cells to migrate upon antigen stimulation or capture is essential in the promotion of antigen-specific immune responses ${ }^{[70]}$. Lf acts as an alarmin to promote the recruitment and activation of APCs and antigenspecific immune responses. It has also been reported as a novel maturation factor for human dendritic cells ${ }^{[10,71]}$. Lf is a strong mediator of dendritic cell function. This observation, together with the above-described impact on Mfs, suggests that Lf exerts its effect on cells involved in the commitment of pathogens (antigens) and can direct the development of adaptive immunity (Figure 2).

\section{Lactoferrin modulates antigen-specific adaptive immune responses}

A key immunomodulatory function (eg, APC activation, maturation, migration and antigen presentation) that may be mediated by Lf is the bridging of innate and adaptive cell functions for the T- and B- cell responses.

\section{B lymphocytes}

Considerable attention is focused on Lf because of its potential role in the maturation and function of immune system cells ${ }^{[72]}$. Significantly, Lf leads to an increase in the expression of the complement 3 receptor (C3R) and acquisition of surface IgD. Also of importance is the interaction between Lf and the Lf receptor on T- and B-lymphocytes ${ }^{[73]}$. Structural changes in the N-terminal basic region and the basic characteristics of the entire molecule contribute to its interaction with B lymphocytes $^{[74]}$. Oral administration of Lf increases the secretion of $\operatorname{IgA}$ and IgG in murine mucosa with intestinal secretion ${ }^{[75,76]}$. These data suggest that Lf acts on B-cells, which are wellknown antigen presenters, to allow for their subsequent interaction with $\mathrm{T}$ cells, which favors elevation of the antibody response (Figure 2).

\section{Tlymphoc ytes}

The effect of Lf on T-cell populations can be further delineated in terms of the cellular subset that is specifically targeted. The adaptive immune response is dominated by T-cell activity, which includes various functions. T-helper cell type 1 (Th1) and type 2 (Th2) stimulate and activate Mf, resulting in intracellular killing events that eliminate intracellular pathogens ${ }^{[77]}$. Lf can downregulate allergic rhinitis, which reduces inflammatory responses, because it upregulates the expression of Th2, Th17 and regulatory T cells. Lf can promote Th1 responses while inhibiting Th2 responses, and it causes T-cell receptor cross-linking, which leads to the inhibition of T-cell activation, reduces the release of inflammatory factors such as IL-5 and IL-17, and further alleviates the degree of inflammation $^{[78]}$. Lf accelerates T-cell maturation by inducing the expression of CD4 surface markers through the activation of a transduction pathway ${ }^{[79]}$. The expression of Lf receptors has been reported in all T-cell subsets. Bovine and human Lf is capable of binding to surface receptors on the human T-cell line (Jurkat) ${ }^{[73,80]}$. These associated changes to the surface of molecules that regulate T-cell function suggest that Lf is capable of modulating $\mathrm{T}$ cell and NK cell activity due to T-cell proliferation. Indeed, Lf can potentiate the restoration of the 


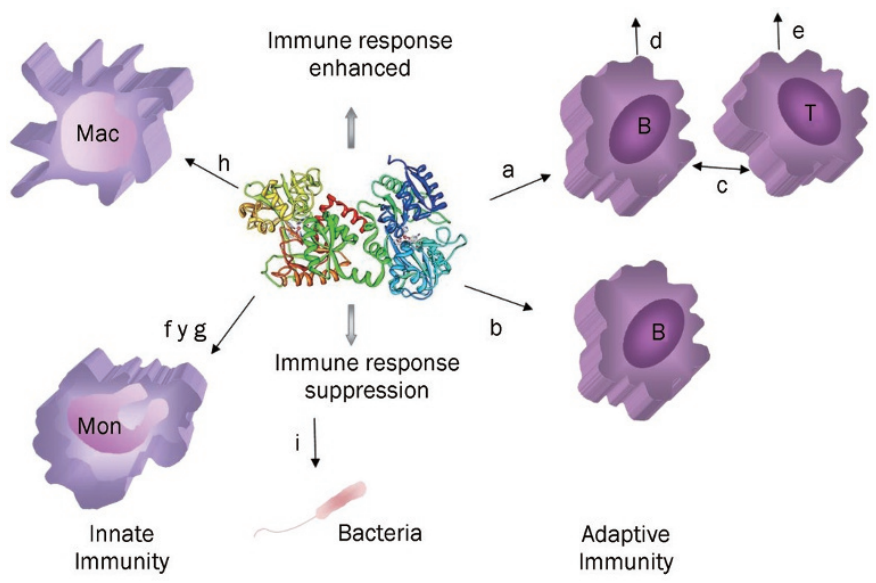

Figure 2. Schematic representation of the influence of host Lf on immune cells. (a) Promotes B- and T-lymphocyte maturation; (b) Negative regulation of B-lymphocytes through LPS binding; (c) B- and T-lymphocyte interaction; (d) induces IgA and IgG secretion; (e) promotes T-lymphocyte proliferation; (f) decreases IL5 and IL10 secretion; (g) down regulates NFK $\beta$ activation of monocytes; ( $h$ ) enhances the phagocytic activity of macrophages; and (i) prevents the interaction between LPS and CD14 as a TLR4. B, B lymphocytes; T, T lymphocytes; Mf, macrophages; Mon, Monocytes; Neu, Neutrophils.

humoral immune response of the host, suggesting a possible mechanism for cell reconstitution through proliferative pathways $^{[63]}$. Lf induces Th1 polarization in diseases in which the ability to control infection or tumor relies on a strong immune response; however, Lf may also reduce Th1 cytokines to prevent excessive inflammatory responses ${ }^{[81]}$.

\section{Response against microorganisms}

The antimicrobial effects of Lf have been demonstrated in vivo for the parenteral administration of Lf in several experimental animal models, most notably in mice ${ }^{[82]}$. Additionally, studies have shown that bovine Lf reinforces the immune system and antioxidant status in healthy human volunteers ${ }^{[83]}$. Furthermore, several in vitro studies have indicated that the structure of Lf plays a vital role in antimicrobial activity (eg, the interaction with viruses and bacterial toxins) because the glycosylation sites of the Lf protein expose its outer surface and allow it to maintain contact with microorganisms ${ }^{[54]}$. Some of the mechanisms through which Lf triggers an immune response against pathogens are summarized in Table 1.

\section{Anti-bacterial activity}

It is well known that Lf interacts directly with bacterial LPS, thereby preventing interaction between the endotoxin-containing LPS binding protein (LBP) and CD14 ${ }^{[8,85]}$. In addition, this Lf-LPS interaction triggers a signaling cascade that results in the release of pro-inflammatory mediators, such as cytokines and chemokines, as well as small molecules, such as lipid mediators and reactive oxygen species ${ }^{[48]}$. In addition to LPS, other pro-inflammatory microbial molecules (eg, unmethylated CpG-containing oligonucleotides) can be neutralized by Lf.
Table 1. Lactoferrin immune response against pathogens.

\begin{tabular}{lcl}
\hline $\begin{array}{l}\text { Mechanism of } \\
\text { action of Lf }\end{array}$ & Target & Reference \\
\hline Enhancing of & Gram-Positive bacteria & $6,84,121,122$, \\
phagocytosis & S mutans & 54,84 \\
& S epidermidis & \\
S aureus & \\
& Gram-Negative bacteria: & \\
& P aeruginosa & \\
& B cepacia & \\
& Porphyromonas gingivalis \\
& Virus: \\
VSV (Vesicular Stomatitis Virus) & Fungi: \\
Candida spp. & A Fumigatus \\
& Parasites: \\
E histolytica & B caballi \\
T cruzi
\end{tabular}

with the host
Biofilms
inhibition

Positive

domain union

with negative

charges on

microorganisms

Modification of

the interactions

of microbes,

cells, or with

the extracellular

matrix
Gram-Negative bacteria:

Porphyromonas gingivalis

Prevetella intermedi

$P$ aeruginosa

$B$ cepacia

B cenocepacia

E coli

$M$ bovis

Gram-Positive bacteria:

$S$ epidermidis

Gram-Negative bacteria:

E coli

Parasites:

$T$ gondii

E stiedai

Gram-Positive bacteria:
B subtilis
K pneumoniae
S mutans
Virus:
Rotavirus
Enterovirus

Inhibits LPS-mediated Gram-Negative bacteria activation

Induction of apoptosis Fungi:

Candida albicans
$84,87,92,123$

6,124

84,87

$6,85,125$

90
The ability to bind unmethylated CpG-containing oligonucleotides allows Lf to have anti-inflammatory effects on B-cells, which supports the possibility that Lf may interact with TLR- 
$9^{[17,86]}$. This mechanism is attributed to the N-terminal domain of Lf and its ability to bind large amounts of iron ${ }^{[84,87]}$, thereby preventing the host cell from inhibiting the production of proinflammatory cytokines (eg, TNF-a, IL-1 $\beta$, IL-6 and IL-8) ${ }^{[6,54]}$. The contribution of Lf to pro-inflammatory cytokine release enhances phagocytosis and cell adhesion and provides protection against pathogens and their metabolites ${ }^{[17,87]}$. However, when Lf is orally administered in Staphylococcus aureusinfected models, an increase in the host response can be observed as an increase in TNF-alevels and decrease in IL-5 and IL-10 levels ${ }^{[17]}$.

\section{Antiviral activity}

Although Lf only exerts its antiviral activity against enveloped viruses, it is currently believed that it has antiviral activity against a broad spectrum of RNA and DNA viruses. Its main contribution to this antiviral defense is the ability to bind to cell membrane glycosaminoglycans ${ }^{[39,87]}$. In the presence of some viruses (eg, vesicular stomatitis virus), Lf can increase the phagocytic activity of $\mathrm{Mfs}^{[17]}$. On the other hand, Lf has strong interactions with the protein gp120 of the Human Immunodeficiency Virus, wherein Lf binds to the DC-SING receptor of dendritic cells to block their interactions and subsequently inhibit the transmission of the virus ${ }^{[6,88]}$.

\section{Antifungal activity}

Candida albicans is one of the most common causes of vaginal infections ${ }^{[89]}$. The adherence of this fungus to the vaginal epithelium can be prevented by the action of Lf because of its ability to sequester iron ${ }^{[87]}$. In addition, Lf has the ability to induce apoptosis in yeast, which was first reported by Madeo et al in $1997^{[90]}$. In 2000, Wakabayashi et al reported that Lf inhibits the in vivo growth of Trichophyton mentagrophytes and Trichophyton rubrum, two of the principal etiological agents of dermatophytosis ${ }^{[1]}$. This growth inhibition occurs because Lf enhances the inflammatory response involved in the cell-mediated immunity that is required to cure this myco$\operatorname{sis}^{[92]}$.

\section{Antiparasitic activity}

The mechanisms involved in the antiparasitic activity of Lf are complex ${ }^{[93]}$. Lf exhibits activity against Entamoeba histolytica, Trichomonas faetus, Trypanosoma cruzi, Trypanozoma brucei, Plasmodium falciparum, Toxoplasma gondii and Eimeria stiedai. It is not clear whether the antimicrobial properties of Lf are related to its direct action against microbes or to the activation of the immune system, but several lines of evidence now indicate that both forms of action are involved. This hypothesis is supported by reports that Lf can modulate and direct changes in the balance of T-cell immunity. In studies involving Toxoplasma gondii infection, oral administration of Lf promotes Th2 cell responses in the intestinal mucosa, which is characterized by decreased levels of IFN- $\gamma$ and elevated levels of IL- $10^{[6,17]}$.

\section{Lactoferrin from other species}

As we discussed in a previous paper ${ }^{[87]}$, the different benefits of Lf have led us to be interested in using molecular strategies to develop recombinant Lf from different species to increase its availability. Because of its broad antimicrobial capacity, Lf could be used as a nutraceutical protein or adjuvant drug. Although colostrum contains high Lf levels, industrial companies will require the production or purification of Lf without affecting the alimentary industry uses of milk. Currently, highly purified bovine lactoferrin (bLf) and human lactoferrin (hLf) can be produced ${ }^{[93]}$. In addition, lactoferrin from other species (eg, mouse, rat, chimpanzee, boar, sheep, goat, buffalo, camel and dog) was sequenced and found to vary by 2112 to $2530 \mathrm{bp}^{[94,95]}$. It has been possible to produce recombinant $\mathrm{Lf}$ specific to human, bovine, equine, porcine, caprine, yak and Kunming by using various expression systems (eg, bacteria, fungi, yeast, cell lines, insects, mammals and plants). While Lf is produced in quantities ranging from $0.756 \mathrm{mg} / \mathrm{L}$ to 10.6 $\mathrm{g} / \mathrm{L}$, human Lf remains the most expressed among all of the different expression systems ${ }^{[87,96-103]}$.

\section{Future applications of lactoferrin}

Lf has multiple activities, it can bind a significant number of compounds and substances, such as lipopolysaccharides, heparin, glycosaminoglycans, DNA and metal ions (eg, $\mathrm{Fe}, \mathrm{Al}, \mathrm{Mn}$, $\mathrm{Co}, \mathrm{Cu}, \mathrm{Zn})^{[39,104]}$; is involved in iron homeostasis; has a wide range of antimicrobial activity against bacteria, virus, fungi and parasites; and has anti-inflammatory, immunomodulatory, anticarcinogenic and enzymatic activities ${ }^{[105]}$. Antibiotic-resistant microorganisms are extremely dangerous to humans, and extensive scientific research has resulted in the development of new antibiotics with different effects in an effort to solve the issue. The scientific community has targeted Lf as a promising candidate to help break the vicious cycle of antibiotic resistances ${ }^{[5,106]}$. Oral Lf supplementation in human newborns can prevent infection or decrease the severity of an existing infection $^{[107-109]}$. A human study found that nutritional supplementation with colostrum was equally efficient in preventing episodes of the flu compared to a vaccine ${ }^{[29,110]}$. In clinical trials, the administration of bovine Lf suppressed carcinogenesis in the colon and other organs, and human studies have recently shown that Lf inhibits the growth of adenomatous polyps and can reduce the risk of colon carcinogenesis ${ }^{[11]}$. The ability of Lf affecting metabolism by reducing triacylglycerol and cholesterol levels have been reported ${ }^{[122]}$, and a study in Japan has revealed that the use of oral Lf can reduce visceral fat in humans ${ }^{[113]}$. Lf-derived peptides with antihypertensive effects have shown similar effects as specific drugs ${ }^{[114]}$. In addition to its application to human health, Lf has industrial application. One study has shown that Lf can be used to extend the shelflife of various meat patties and other meat products, and fresh ground pork with added Lf had lower total plate counts ${ }^{[115]}$. Lf can also be used as an alternative animal feed additive that can reduce or eliminate the impact of antibiotic consumption on animal husbandry and strengthen the natural immune 
systems of livestock. Along these lines, a study found that early weaned piglets receiving rice bran expressing porcine recombinant-Lf as a feed additive had improved antimicrobial characteristics and IgG concentration ${ }^{[116-118]}$. Additionally, Lf could be used to control diseases caused by fungal pathogens in crops $^{[119,120]}$. In cell culture applications, a concern regarding potential contamination when using protein and peptides from animals exists; therefore, the expression of recombinant Lf in rice has been studied to enhance the growth of intestinal cells, hybridoma cells, human embryonic kidney cells and osteoblasts. This study concluded that Lf is effective in promoting mammalian cell growth and increasing cell productivity $^{[121]}$.

Human Lf is safe and is considered by the FDA as a GRAS product with no contraindications in either pediatric or adult patients ${ }^{[82,106]}$. Some pharmaceutical industries (eg, Venture LLC, Biopharming, Ventria Bioscience, AusBioMed, Max Biocare, Morinaga Milk Industry Co LTD) are currently commercializing human and bovine Lf in different products including a nutraceutical powder, a vitamin supplement for children, infant formula, beverages and a cell growth promoter. The bio-pharmacy company Agennix has a product, talactoferrin, which is currently undergoing clinical trials for consideration as a GRAS product. This product is proposed for use in the treatment of diverse carcinomas, severe sepsis and diabetic foot ulcers. Infant formulas supplemented with Lf are among the products in which industry is particularly interested.

\section{Conclusion}

Lf is a versatile molecule that was molded by natural selection to be a first-line defense in mammals. Its ability to exert multiple regulatory effects due to its cationic nature allows it to bind a large number of surface molecules or metal ions during the development of microorganisms and induce host immunemodulatory activation, which influences the adaptive and innate immunities. The development of Lf expression systems for food and pharmaceutical applications are required, due to its plethora of abilities as a multifunctional, nutraceutical protein.

\section{Acknowledgements}

This work was supported in part by an internal grant from Facultad de Ciencias Químicas, Universidad Autónoma de Chihuahua, Mexico and Proteo/Muuu-Technologies de México.

\section{References}

1 Groves ML. The isolation of a red protein from milk. JACS 1960; 82: 3345-50.

2 Montreuil J, Tonnelat J, Mullet S. Preparation and properties of lactotransferrin of human milk. BBA 1960; 45: 413-21.

3 Walker A. Breast milk as the gold standard for protective nutrients. J Pediat 2010; 156: 3-7.

4 Van Der Strate BWA, Belijaars L, Molema G. Antiviral activities of lactoferrin. Antiviral Res 2001; 52: 225-39.

5 Valenti A, Antonini G. Lactoferrin: an important host defense against microbial and viral attack. Cell Mol Life Sci 2005; 62: 2576-87.
6 Legrand D, Pierce A, Elass E, Carpentier M, Mariller C, Mazurier J. Lactoferrin structure and functions. Adv Exp Med Biol 2008; 606: 163-94.

7 Kawamata T, Tooyama I, Yamada T, Walker DG, McGeer PL. Lactotransferrin immunocytochemistry in Alzheimer and normal human brain. Am J Pathol 1993; 142: 1574-85.

8 Uchida K, Matsuse R, Tomita S. Immunochemical detection of human lactoferrin in feces as a new marker for inflammatory gastrointestinal disorders and colon cancer. Clin Biochem 1994; 27: 25964.

9 van de Graaf EA, Out TA, Kobesen A, Jansen HM. Lactoferrin and secretory IgA in the bronchoalveolar lavage fluid from patients with a stable asthma. Lung 1991; 169: 275-83.

10 de la Rosa G, Yang D, Tewary P, Varadhachary A, Oppenheim JJ. Lactoferrin acts as an alarmin to promote the recruitment and activation of APCs and antigen-specific immune responses. J Immunol 2008; 180: 6868-76.

11 Baveye S, Elass E, Mazurier J, Spik G, Legrand D. Lactoferrin: A multifunctional glycoprotein involved in the modulation of the inflammatory process. Clin Chem Lab Med 1999; 37: 281-6.

12 Legrand D, Elass E, Carpentier M, Mazurier M. Lactoferrin: a modulator of immune and inflammatory responses. Cell Mol Life Sci 2005; 62: 2549-59.

13 Fillebeen C, Ruchoux M, Mitchell V, Vincent S, Benaïssa M, Pierce A. Lactoferrin is synthesized by activated microglia in the human substantia nigra and its synthesis by the human microglial CHME cell line is upregulated by tumor necrosis factor alpha or 1-methyl4-phenylpyridinium treatment. Brain Res Mol Brain Res 2001; 96: 103-13.

14 Wagner KR, Sharp FR, Ardizzone TD, Lu A, Clark JF. Heme and Iron Metabolism: Role in cerebral hemorrhage. J Cerebral Blood Flow Metabol 2003; 23: 629-52.

15 Kell DB. Iron behaving badly: inappropriate iron chelation as a major contributor to the aetiology of vascular and other progressive inflammatory and degenerative diseases. BMC Med Genomics 2009; $2: 2$.

16 Kruzel ML, Bacsi A, Choudhury B, Sur S, Boldogh I. Lactoferrin decreases pollen antigen-induced allergic airway inflammation in a murine model of asthma. Immunol 2006; 119: 59-66.

17 Actor J, Hwang S, Kruzel M. Lactoferrin as a natural immune modulator. Curr Pharm Des 2009; 15: 1956-73.

18 Lu YC, Yeh WC, Ohashi PS. LPS / TLR4 signal transduction pathway. Cytokine 2008; 42: 145-51.

19 Ando K, Hasegawa K, Shindo K, Furusawa T, Fujino T, Kikugawa K. Human lactoferrin activates NF-kappaB through the Toll-like receptor 4 pathway while it interferes with the lipopolysaccharide-stimulated TLR4 signaling. FEBS J 2010; 277: 2051-66.

20 Yen CC, Shen CJ, Hsu WH, Chang YH, Lin HT, Chen HL, et al. Lactoferrin: an iron-binding antimicrobial protein against Escherichia coli infection. Biometals 2011; 24: 585-94.

21 Ahmad I, Owais M, Shahid M, Aqil F. Combating Fungal Infections. In: Problems and remedy. Springer-Verlag Berlin Heidelberg 2010. p 397-422.

22 Wiesner J, Vilcinskas A. Antimicrobial Peptides. The ancient arm of the human immune system. Virulence 2010; 1: 440-64.

23 Lai Y, Gallo RL. AMPed Up immunity: how antimicrobial peptides have multiple roles in immune defense. Trends Immunol 2009; 30: 131-41.

24 Smit E, Oberholzer HM, Pretorius E. A review of immunomodulators with reference to Canova. Homeopathy 2009; 98: 169-76.

25 Abbas A, Lichtmam A, Pillai S. Inmunología cellular y molecular. 6th 
edition Elsevier; 2008.

26 Rovere-Querinim P, Capobianco A, Scaffidi P, Valentinis B, Catalanotti $\mathrm{F}$, Giazzon $\mathrm{M}$, et al. HMGB1 is an endogenous immune adjuvant released by necrotic cells. EMBO Rep 2004; 5: 825-30.

27 Arya V, Kumat G. A review of marine immunomodulators. Int J Pharm Life Sci 2011; 2: 751-8.

28 Sharma R, Rohilla A, Arya V. A short review on pharmacology of plant immunomodulators. IJPSRR 2011; 9: 126-31.

29 Benson KF, Carter SG, Patterson KM, Patel D, Jensen GS. A novel extract from bovine colostrum whey supports anti-bacterial and antiviral innate immune functions in vitro and in vivo. Prev Med 2012; 54: 116-23.

30 Manzoni P, Decembrino L, Stolfi I, Pugni L, Rinaldi M, Cattani S, et al. Lactoferrin and prevention of late-onset sepsis in the pre-term neonates. Early Hum Dev 2010; 86: 559-61.

31 Tomita M, Wakayabashi H, Shin K, Yamauchi K, Yaeshima T, Iwatsuki $\mathrm{K}$. Twenty-five years of research on bovine lactoferrin applications. Biochimie 2008; 1: 52-7.

32 Hamosh M. Bioactive factors in human milk. Pedriat Clin North Am 2001; 48: 69-86.

33 Holt PG, Jones CA. The development of the immune system during pregnancy and early life. Allergy 2000; 55: 688-97.

34 Lönnerdal B. Bioactive proteins in breast milk. J Paediatr Child Health 2013; 49: 1-7.

35 Liang Y, Wang X, Wu M, Zhu W. Simultaneous isolation of lactoferrin and lactoperoxidase from bovine colostrum by SPEC 70 SLS cation exchange resin. Int J Environ Res Public Health 2011; 8: 3764-76.

36 Nigel F, Wong SH, Hampson P, Wang K, Young SP, Deigner HP, et al. Lactoferrin inhibits neutrophil apoptosis via blockade of proximal apoptotic signaling events. BBA Mol Cel Res 2011; 1813: 1822-6.

37 Migliaccio G, Migliaccio AR, Petti S, Mavilio F, Russo G, Lazzaro D, et al. Human embryonic hemopoiesis. Kinetics of progenitors and precursors underlying the yolk sac to liver transition. J Clin Invest 1986; 78: 51-60.

38 Mak T, Saunders M. Primer to immune Response. Academic Cell. Ed. Elsevier; 2011.

39 Adlerova L, Bartoskova A, Faldyna M. Lactoferrin: a review. Vet Med 2008; 53: 457-68.

40 Sykes JA, Thomas MJ, Goldie DJ, Turner GM. Plasma lactoferrin levels in pregnancy and cystic fibrosis. Clin Chim Acta 1982; 122: 385-96.

41 Levay PF, Viljoen M. Lactoferrin: a general review. Haematologica 1995; 80: 252-67.

42 Holt PG, Sly PD, Björkstén B. Atopic versus infectious diseases in childhood: a question of balance? Pediatr Allergy Immunol 1997; 8: 53-8.

43 Cox TM, Mazurier J, Spik G, Montreuil J, Peters TJ. Iron binding proteins and influx of iron across the duodenal brush border. Evidence for specific lactotransferrin receptors in the human intestine. Biochim Biophys Acta 1979; 588: 120-8.

44 Liao Y, Jiang R, Lönnerdal B. Biochemical and molecular impacts of lactoferrin on small intestinal growth and development during early life. Biochem Cell Biol 2012; 90: 476-84.

45 Liedel JL, Guo Y, Yu Y, Shiou SR, Chen S, Petrof EO, et al. Mother's milk-induced Hsp70 expression preserves intestinal epithelial barrier function in an immature rat pup model. Pediatr Res 2011; 69: 395400.

46 Gordon S. The macrophage: past, present and future. Eu J Immunol 2007; 37: S9-17.

47 Martinez FO, Sica A, Mantovani A, Locati M. Macrophage activation and polarization. Front Biosci 2008; 13: 453-61.
48 Puddu P, Valenti P, Gessani S. Immunomodulatory effects of lactoferrin on antigen presenting cells. Biochimie 2009; 91: 11-8.

49 Banchereau J, Briere F, Caux C, Davoust J, Lebecque S, Liu YJ, et al. Immunobiology of dendritic cells. Annu Rev Immunol 2000; 18 : 767-811.

50 Steinman RM. Some interfaces of dendritic cell biology. APMIS 2003; 111: 675-97.

51 Birgens HS, Hansen NE, Karle H, Kristensen LO. Receptor binding of lactoferrin by human monocytes. Br J Haematol 2008; 54: 383-91.

52 Roseanu A, Chelu F, Trif M, Motas C, Brock JH. Inhibition of binding of lactoferrin to the human promonocyte cell line THP-1 by heparin: the role of cell surface sulphated molecules. Biochim Biophys Acta 2000; 1475: 35-8.

53 Suzuki YA, Lopez V, Lonnerdal B. Mammalian lactoferrin receptors: structure and function. Cell Mol Life Sci 2005; 62: 2560-75.

54 Latorre D, Puddu P, Valenti P, Gessani S. Reciprocal interactions between lactoferrin and bacterial endotoxins and their role in the regulation of the immune response. Toxins 2010; 2: 54-68.

55 Wilk KM, Hwang SA, Actor JK. Lactoferrin modulation of antigenpresenting-cell response to BCG infection. Postepy Hig Med Dosw 2007; 61: 277-82.

56 Gifford JL, Hunter HN, Vogel HJ. Lactoferricin: a lactoferrin-derived peptide with antimicrobial, antiviral, antitumor and immunological properties. Cell Mol Life Sci 2005; 62: 2588-98.

57 Hwang SA, Wilk KN, Bangale YA, Kruzel ML, Actor JK. Lactoferrin modulation of IL-12 and IL-10 response from activated murine leukocytes. Med Microbiol Immunol 2007; 196: 171-80.

58 Schmitt E, Hoehn P, Huels C, Goedert S, Palm N, Rüde E, et al. T helper type 1 development of naive CD4+ T cells requires the coordinate action of interleukin-12 and interferon-gamma and is inhibited by transforming growth factor-beta. Eur J Immunol 1994; 24: 793-8.

59 Gately MK, Renzetti LM, Magram J, Stern AS, Adorini L, Gubler U, et al. The interleukin-12/interleukin-12-receptor system: role in normal and pathologic immune responses. Annu Rev Immunol 1998; 16 : 495-521.

$60 \mathrm{Kim}$ CW, Lee TH, Park KH, Choi SH, Kim J. Human lactoferrin suppresses TNF-a-induced intercellular adhesion molecule-1 expression via competition with NF-KB in endothelial cells. FEBS Lett 2012; 586: 229-34.

61 Bagby GC, Rigas VD, Bennett RM, Vandenbark AA, Garewal HS. Interaction of lactoferrin, monocytes, and T lymphocyte subsets in the regulation of steady-state granulopoiesis in vitro. J Clin Invest 1981; 68: 56-63.

62 Radhakrishnan S, Wiehagen KR, Pulko V, Van Kuelen V, Faubion WA, Knutson KL, et al. Induction of a Th1 response from Th2-polarized T cells by activated dendritic cells: dependence on TCR: peptide-MHC interaction, ICAM-1, IL-12, and IFN-gamma. J Immunol 2007; 178: 3583-92.

63 Artyma J, Zimeckia M, Kruzel ML. Reconstitution of the cellular immune response by lactoferrin in cyclophosphamide-treated mice is correlated with renewal of T cell compartment. Immunobiology 2003; 207: 197-205.

64 Ward PP, Uribe-Luna S, Conneely OM. Lactoferrin and host defense. Biochem Cell Biol 2002; 80: 95-102.

65 Moser M, Murphy KM. Dendritic cell regulation of Th1-Th2 development. Nat Immunol 2000; 1: 199-205.

66 Hallman M, Rämet M, Ezekowitz RA. Toll-like receptors as sensors of pathogens. Pediatr Res 2001; 50: 315-21.

67 Biragyn A, Ruffini PA, Leifer CA, Klyushnenkova E, Shakhov A, Chertov $O$, et al. Toll-like receptor 4-dependent activation of dendritic cells by 
beta-defensin 2. Science 2002; 298: 1025-9.

68 Hwang SA, Kruzel ML, Actor JK. Lactoferrin augments BCG vaccine efficacy to generate $T$ helper response and subsequent protection against challenge with virulent Mycobacterium tuberculosis. Int Immunopharmacol 2005; 5: 591-9.

69 Saidi H, Eslahpazir J, Carbonneil C, Carthagena L, Requena M, Nassreddine $\mathrm{N}$, et al. Differential modulation of human lactoferrin activity against both R5 and X4-HIV-1 adsorption on epithelial cells and dendritic cells by natural antibodies. J Immunol 2006; 177: 5540-9.

70 Toebak MJ, de Rooij J, Moed H, Stoof TJ, von Bloomberg BM, Bruynzeel DP, et al. Differential suppression of dendritic cell cytokine production by anti-inflammatory drugs. Br J Dermatol 2008; 158: 225-33.

71 Spadaro M, Caorsi C, Ceruti P, Varadhachary A, Forni G, Pericle F, et al. Lactoferrin, a major defense protein of innate immunity, is a novel maturation factor for human dendritic cells. FASEB J 2008; 22: 2747-57.

72 Zimecki M, Kapp J, Machnicki M, Zalguski T, Wlaszczyk A, Kübler A, et al. Lactoferrin. Its role in maturation and function of cells of the immune system and protection against shock in mice. Adv Exp Med Biol 1998; 443: 331-6.

73 Legrand D, van Berkel PH, Salmon V, van Veen HA, Slomianny MC, Nuijens $\mathrm{JH}$, et al. The $\mathrm{N}$ terminal Arg2, Arg3 and Arg4 of human lactoferrin interact with sulphated molecules but not with the receptor present on Jurkat human lymphoblastic T-cells. Biochem J 1997; 327: 841-6.

74 Kawasaki Y, Sato K, Shinmoto H, Dosako S. Role of basic residues of human lactoferrin in the interaction with $B$ lymphocytes. Biosci Biotechnol Biochem 2000; 62: 314-8.

75 Sfeir RM, Dubarry M, Boyaka PN, Rautureau M, Tomé D. The mode of oral bovine lactoferrin administration influences mucosal and systemic immune responses in mice. J Nutr 2004; 134: 403-9.

76 Zimecki M, Mazurier J, Spik G, Kapp JA. Lactoferrin inhibits proliferative response and cytokine production of Th1 but not Th2 cell lines. Arch Immunol Ther Exp 1996; 44: 51-6.

77 Hwang S, Welsh K, Kruzel ML, Actor JK. Lactoferrin augmentation of the BCG vaccine leads to increase pulmonary integrity. Tuberc Res Treat 2011; 2011: 835410.

78 Wang S, Deng Y, Ren J, Xiao B, Chen Z, Tao Z. Lactoferrin administration into the nostril alleviates murine allergic rhinitis and its mechanisms. Scandinavian J Immun 2013; 78: 507-15.

79 Dhennin-Duthille I, Masson M, Damiens E, Fillebeen C, Spik G, Mazurier J. Lactoferrin upregulates the expression of CD4 antigen through the stimulation of the mitogen-activated protein kinase in the human lymphoblastic T Jurkat cell line. J Cell Biochem 2000; 79: 583-93.

80 Bi BY, Lefebvre AM, Dus D, Spik G, Mazurier J. Effect of lactoferrin on proliferation and differentiation of the Jurkat Human lymphoblastic $T$ cell line. Arch Immunol Ther Exp 1997; 45: 315-20.

81 Kuhara T, Ligo M, Itoh T, Ushida Y, Sekiene K, Terada N, et al. Orally administered lactoferrin exerts an antimetastatic effect and enhances production of IL-18 in the intestinal epithelium. Nutr Cancer 2000; 38: 192-9.

82 Drago ME. Lactoferrina: producción industrial y aplicaciones. Rev Mex Ciencias Farmacéuticas 2007; 38: 30-8.

83 Legrand D, Mazurier J. A critical review of the roles of host lactoferrin in immunity. Biometals 2010; 23: 365-7.

84 Jenssen H, Hancock R. Antimicrobial properties of lactoferrin. Biochimie 2009; 91: 19-29.

85 Yang D, de la Rosa G, Tewary P, Oppenheim JJ. Alarmins link neutrophils and dendritic cells. Trends Immunol 2009; 30: 531-7.

86 Mulligan P, White N, Monteleone G, Wang P, Wilson J, Ohtsuka Y, et al. Breast milk lactoferrin regulates gene expression by binding bacterial DNA CpG motifs but not genomic DNA promoters in model intestinal cells. Pediatr Res 2006; 59: 656-60.

87 García-Montoya IA, Siqueiros-Cendon T, Arévalo-Gallegos S, RascónCruz Q. Lactoferrin a multiple a bioactive protein: an overview. Biochim Biophys Acta 2012; 1820: 226-36.

88 Berlutii F, Pantanella F, Natalizi T, Froni A, Paesano R, Polimeni A, et al. Antiviral properties of lactoferrin a natural immnunity molecule. Molecules 2011; 16: 6992-7018.

89 Al-Sheikh H. Effect of lactoferrin and iron on the growth of human pathogenic candida species. Pak J Biol Sci 2009; 12: 91-4.

90 Andrés M, Viejo M, Fierro J. Human lactoferrin induces apoptosis-like cell death in Candida albicans: critical role of k-channel-mediated $\mathrm{k}$ efflux. Antimicrob Agents Chemother 2008; 52: 4081-8.

91 Bonifaz A. In Micología Médica Básica. McGraw Hill 3rd editión. 2010; 59-97.

92 Wakabayashi H, Yamauchi K, Kobayashi T, Yaeshima T, Iwatsuki $\mathrm{K}$, Yoshie $\mathrm{H}$. Inhibitory effects of lactoferrin on growth and biofilm formation of Porphyromonas gingivalis and Prevotella intermedia. Antimicrob Agents Chemother 2009; 53: 3308-16.

93 Kaufman DA. Lactoferrin supplementation to prevent nosocomial infection in preterm infants. JAMA 2009; 302: 1467-8.

94 Masson PL, Heremans JF. Lactoferrin in milk from different species. Comp Biochem Phisiol 1971; 39: 119-29.

95 Kang JF, Li XL, Zhou RY, Li LH, Feng FJ, Gou XL. Bioinformatics analysis of lactoferrin gene for several species. Biochem Genet 2008; 46: 312-22.

96 Choi SM, Lee OS, Kwon SY, Kwak SS, Yu DY, Lee HS. High expression of a human lactoferrin in transgenic tobacco cell cultures. Biotechnol Lett 2003; 25: 213-8.

97 Nguyen TC, Lakshaan DK, Han J, Galvez L, Mitra A. Transgenic plant expressing antimicrobial lactoferrin protein are resistant to a fungal pathogen. J Plant Mol Biol Biotechnol 2011; 2: 1-8.

98 Paramasivam M, Saravanan K, Uma K, Sharma S, Singh TP, Srinivasan A. Expression, purification and characterization of equine lactoferrin in Pichia pastoris. Protein Expres Purif 2002; 26: 28-34.

99 Wang SH, Yang TS, Lin SM, Tsai MS, Wu SC, Mao S. Expression, characterization and purification of recombinant porcine lactoferrin in Pichia pastoris. Protein Expres Purif 2002; 25: 41-9.

100 Chen GH, Yin LJ, Chiang IH, Jiang ST. Expression and purification of goat lactoferrin form Pichia pastoris expression system. J Food Sci 2007; 72: M67-71.

101 Dong ZY, Zhang YZ. Molecular cloning and expression of yak (Bos grunniens) lactoferrin cDNA in Pichia pastoris. Biotechnol Lett 2006; 28: $1285-92$.

102 Wang J, Tiang Z, Teng D, Yang Y, Hu J, Wang J. Cloning expression and characterization of kumming mice lactoferrin and its $\mathrm{N}$-Lobe. Biometals 2010; 23: 523-30.

103 Garcia-Montoya I, Chávez-González S, Salazar-Martinez J, ArévaloGallegos S, Sinawaga-Garcia S, Rascón-Cruz Q. Expression and characterization of recombinant bovine lactoferrin in $E$ coli. Biometals 2013; 26: 113-22.

104 Baker EN. Structure and reactivity of transferrins. Adv Inorganic Chem 1994; 41: 389-463.

105 Ward PP, Paz E, Conneely OM. Mulifunctional roles of lactoferrin: a critical overview. Cell Mol Life Sci 2005; 62: 2540-8.

106 Goldman IL, Deikin AV, Sadchikova ER. Human lactoferrin can be alternative to antibiotics. In: Proceedings of the World Medical Conference 2010; 27-38. 
107 Manzoni P, Rinaldi M, Cattani S, Pugni L, Romeo MG, Messner H, et al. Bovine lactoferrin supplementation for prevention of late-onset sepsis in very low-birth-weight neonates. JAMA 2009; 302: 1421-8.

108 Venkatesh MP, Abrams S. Oral lactoferrin for the prevention of sepsis and necrotizing enterocolitis in preterm infants. Cochrane Database Syst Rev 2010; 12: CD007137.

109 Zavaleta N, Figueroa D, Rivera J, Sánchez J, Alfaro S, Lönnerdal B. Efficacy of rice-based oral rehydration solution containing recombinant human lactoferrin and lysozyme in Peruvian children with acute diarrhea. J Pediat Gastroenterol Nut 2007; 44: 258-64.

110 Yoshioka Y, Kudo S, Nishimura H, Yajima T, Kishihara K, Saito K, et al. Oral administration of bovine colostrum stimulates intestinal intraepithelial lymphocytes to polarize Th1-type in mice. Int Immunopharmacol 2005; 5: 581-90.

111 Tsuda H, Koszu T, Linuma G, Ohashi Y, Saito Y, Saito D, et al. Cancer prevention by bovine lactoferrin: from animal studies to human trial. Biometals 2010; 23: 399-409.

112 Takeuchi T, Shimizu H, Ando K, Harada E. Bovine lactoferrin reduces plasma triacylglycerol and NEFA accompanied by decreased hepatic cholesterol and triacylglycerol contents in rodents. Br J Nut 2004; 91: 533-8.

113 Ono T, Murakoshi M, Suzuki N, lida N, Ohdera M, ligo M, et al. Potent anti-obesity effect of enteric-coated lactoferrin: derease in visceral fat accumulation in Japanese men and women with abdominal obesity after 8-week administration of enteric-coated lactoferrin tablets. $\mathrm{Br} \mathrm{J}$ Nut 2010; 104: 1688-95.

114 Ruiz-Giménez P, Salom JB, Marcos JF, Valles S, Martinez-Maqueda D, Recio I, et al. Antihypertensive effect of bovine lactoferrin pepsine hydrolysate: Identification of novel active peptides. Food Chem 2012; 131: 266-73.

115 Umuhumuza LC, Wei-min N, Sun X. Effect of bovine lactoferrin and casein peptide powder on microbial growth and glucose utilization by microorganism in pork meat during storage at $4{ }^{\circ} \mathrm{C}$. Pak J Nutr 2011; 10: 208-13.

116 Humphrey BD, Huang N, Klasing KC. Rice expressing lactoferrin and lysozyme has antibiotic-like properties when fed to chicks. J Nutr 2002; 132: 1214-8.

117 Shan T, Wang Y, Liu J, Xu Z. Effect of dietary lactoferrin on the immune functions and serum iron level of weaning piglets. J Anim Sci 2007; 85: 2140-6.

118 Lee TT, Chang CC, Juang RS, Chen RB, Yang HY, Chu LW, et al. Porcine lactoferrin expression in transgenic rice and its effects as a feed additive on early weaned piglets. J Agri Food Chem 2010; 58 : 5166-73.

119 Wang J, Xia XM, Wang HY, Li PP, Wang KY. Inhibitory effect of lactoferrin against gray mould on tomato plants caused by Botrytis cnerea and possible mechanism of action. Int J Food Microbiol 2013; 161: 151-7.

120 Huang N, Bethell D, Card C, Cornish J, Marchbank T, Wyatt D, et al. Bioactive recombinant human lactoferrin, derived from rice, stimulates mammalian cell growth. In Vitro Cell Dev Biol Anim 2008; 44: 464-71.

121 Leon N, Reyes M, Ordaz C, de la Garza M. Microbicidal action of lactoferrin and lactoferricin and their synergistic effect with metronidazole in Entamoeba histolytica. Biochem Cell Biol 2006; 84: 327-36.

122 Ikadai H, Tanaka T, Shibahara N, Tanaka H, Matsuu A, Kudo N, et al. Inhibitory effect of lactoferrin on in vitro growth of Babesia caballi. Am J Trop Med Hyg 2005; 73: 710-2.

123 Wakabayashi H, Uchida K, Yamauchi K, Teraguichi S, Hayasawa H, Yamaguchi $H$. Lactoferrin given in food facilitates dermatophytosis cure in guinea pigs models. Antimicrob Agents Chemother 2000; 47: 595-601.

124 Baker E, Baker H, Kidd R. Lactoferrin and transferrin: Functional variations on a common structural framework. Biochem Cell Biol 2008; 80: 27-34.

125 Puddu P, Latorre D, Valenti P, Gressani S. Immunoregulatory role of lactoferrin-lipopolysaccharid interactions. Biometals 2010; 23 : 387-97. 